\title{
POLYPLOID EVOLUTION AND MAMMALIAN CHROMOSOMES
}

\author{
LEO SACHS \\ John Innes Horticultural Institution \\ Bayfordbury, Hertford, Herts.
}

\section{INTRODUCTION}

Received 30.iv.52

Mammalian chromosomes are, with some justification, generally considered difficult to study. Adequate techniques are thus of even more importance than with more favourable material. Faulty observations, even within recent years, have often been the direct result of poor techniques. Yet developments in the handling of mammalian chromosomes have lagged far behind the progress made by the smear and squash techniques which are used for plants. Section cutting by the microtome is still the rule for mammals with the osmium chromic mixtures, introduced by Minouchi (Darlington and La Cour, I947) as the most commonly used fixative. After many years of work on mammalian chromosomes, Matthey (r95 Ia) has in fact come to the conclusion that the Minouchi technique-" and only this technique "- -gives good results with mammals.

Many species of mammals have a large number of small chromosomes. Apart from any labour saving in the absence of section cutting, squash techniques are thus often necessary for correct observations. The Minouchi type of fixative does not, however, lend itself well to the making of squashes. I have therefore examined a variety of mammals in order to study the possibility of making good squash preparations from the testes. This study has shown that a simple squash technique, far from being inferior to the Minouchi method followed by section cutting, can produce better results.

I have been able to check chromosome numbers in this way and some previously recorded numbers proved to be incorrect. Correct determination has further shown a clear example of polyploid evolution in mammals which had previously been overlooked.

There are thus different reports of chromosome numbers and different reports of techniques. These involve a conflict about facts. On the other hand, the supposed absence of polyploids (Muller, 1940) and the supposed value of "fundamental numbers" (Matthey, I95I $a$ ) involve a conflict about theory. Application of the correct techniques has given the correct chromosome number. Application of the correct theory has given the correct explanation.

\section{TECHNIQUE}

A simple squash method can be used for both mitosis and for 357 
meiosis. Good results with testes were sometimes obtained by fixation in aceto-carmine followed by the normal method of Feulgen staining. But the aceto-carmine did not always produce an adequate fixation. Good results for testes could, however, always be obtained merely by fixation in acetic-alcohol ( $1: 3$ ) followed by Feulgen staining and squashing. There was also no difficulty in making the slides permanent.

The condition of the animal is important for obtaining satisfactory preparations. Good results for mitosis can be most easily obtained by using young animals soon after birth. The most suitable age varies with different mammals: it lies in the region of approximately 14 days in those species which have been examined. But the use of young animals is not essential for mitotic figures. Thus in Mesocricetus auratus, the golden hamster, comparable results could be seen both in 2 weeks and in ro weeks old animals. The illustration from the 72 chromosome Tatera indica ceylonica, the Ceylon gerbil, was obtained from an animal approximately $5 \frac{1}{2}$ months old. (The testis material of the Ceylon gerbil was obtained through the courtesy of Dr W. C. Osman Hill of the London Zoo.)

When investigating mammals which must be caught in the wild, it is often not possible to obtain animals of a desirably young age. The mitotic and meiotic activity of such animals also varies at different seasons of the year. Good results by squashing can, however, still be obtained with animals which can not be kept under laboratory conditions. This was found e.g. in Clethrionomys glareolus, the bank vole ( $2 n=$ $56)$ and in Apodemus sylvaticus, the field mouse, $(2 n=48)$, which were caught in the grounds of Bayfordbury in January $195^{2}$.

This simple squash technique has given uniformly good results in young animals which can be bred in the laboratory, and in older animals which were bred in the laboratory or caught in the wild. La Cour (I944) has shown the results that can be obtained from bone marrow by using a modified type of fixation. It is thus not essential to accept the usual pessimistic outlook on the study of mammalian chromosomes.

\section{THE CHROMOSOMES OF THE HAMSTERS}

The hamsters have been divided by Ellerman (I94I) on the basis of external animal morphology into Mesocricetus, Cricetus, Cricetulus, and Phodopus. There is no data on the chromosomes of Phodopus, but the other three groups have now been examined (table I).

Previous observers had recorded $2 n=38$ for Mesocricetus auratus (Koller, 1938, I946; Muldal, 1947) and 2n=14 for Cricetulus griseus (Pontecorvo, r943; Muldal, I950). White (1945) cited these counts as an extreme example of widely different chromosome numbers in closely related mammals. Both counts are incorrect.

The correct chromosome number of Mesocricetus auratus has been established in young and old males at mitosis and at meiosis. All the golden hamsters in Britain are descended from one original family introduced in 1931 . The difference between the previous observations of $3^{8}$ 
and the present observation of 44 can thus not be explained by assuming the existence of different chromosome races within the species. Husted et al. (I 945) had observed two cells with 44 chromosomes in the ovaries of the female golden hamster and Matthey (195 $\mathrm{I} b$ ) agrees with this count. Husted had considered that the 44 chromosome cells in the ovary possess a constitution abnormal for the species, but there is no doubt that this is the correct chromosome number of the golden hamster.

The observations of Pontecorvo (1943) on the chromosomes of Cricetulus griseus, with its supposed $2 n=14$, have also been found incorrect. I was able to obtain some testis material of this species from Dr M. W. Schwentker of Tumblebrook Farm, New York and have established that it has a chromosome number of $2 n=22$. I have further found that the allied Cricetus cricetus has the same chromosome number of $2 n=22$. Matthey ( $\left.195^{1} b\right)$ also reports $2 n=22$ for Cricetulus griseus and Cricetus cricetus. There is thus no doubt that $2 n=22$ is the correct number for both these species.

The correct chromosome numbers of the hamsters are given in table I.

\section{TABLE I}

\begin{tabular}{|c|c|c|}
\hline Species & $\begin{array}{l}\text { Chromosome } \\
\text { number } \\
(2 n)\end{array}$ & $\begin{array}{l}\text { Number } \\
\text { of } \\
\text { Mammae }\end{array}$ \\
\hline Cricetulus griseus ( & $-\quad 22$ & 8 \\
\hline Cricetus cricetus (co & 22 & 8 \\
\hline Mesocricetus auratus & 44 & $14^{-22}$ \\
\hline
\end{tabular}

\section{THE DEFINITE EXISTENCE OF POLYPLOIDS}

The above evidence shows that the hamsters represent a clear example of polyploidy among related species of mammals. Cricetus and Cricetulus are diploids and Mesocricetus is a tetraploid.

The data from external animal morphology also supports the existence of a sudden major evolutionary step in the origin of Mesocricetus. This can be seen in the number of mammae in the females (table I). Mesocricetus has 14-22 mammae whereas the other hamsters have characteristically 8 mammae. There is no intermediate forms between the hamsters with 8 mammae and the "multimammate" condition in Mesocricetus (Ellerman, I94I). As Mesocricetus has arisen by polyploidy one might expect such a sudden major change without intermediate forms.

That Mesocricetus is of a later derived origin can further be supported by the geological record (Simpson, I945).

\begin{tabular}{|c|c|c|c|}
\hline \multirow{2}{*}{$\begin{array}{c}\text { Diploids } \\
\text { Cricetulus } \\
\text { Cricetus }\end{array}$} & \multicolumn{3}{|c|}{$\begin{array}{c}\text { Earliest Geological Record } \\
\text { Europe }\end{array}$} \\
\cline { 2 - 4 } & $\begin{array}{c}\text { Pleistocene } \\
\text { Pliocene }\end{array}$ & $\longleftarrow$ & $\begin{array}{l}\text { Pliocene } \\
\text { Recent }\end{array}$ \\
\hline $\begin{array}{c}\text { Tetraploid } \\
\text { Mesocricetus }\end{array}$ & - & Recent & - \\
\hline
\end{tabular}


Mesocricetus is only of recent occurrence in Europe and Asia, whereas there are earlier geological records for Cricetulus in Europe and Asia and for Cricetus in Europe. This absence of earlier geological records for Mesocricetus may show that the tetraploid Mesocricetus has only arisen from diploids in the recent period.

It has often been observed in plants that related diploids and tetraploids can differ in their geographical distribution. This difference in distribution is also found in the hamsters. Mesocricetus shows a more limited geographical distribution than Cricetus and Cricetulus (Ellerman, I94I and fig. I). There are some areas in which the diploids and the tetraploid may co-exist. Mesocricetus and Cricetulus have been re-

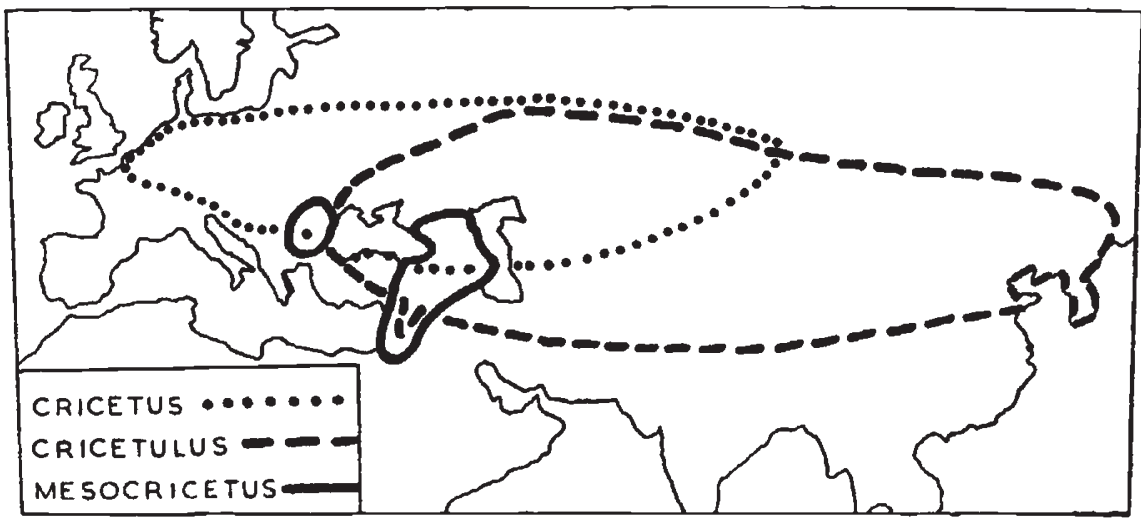

FIG. 1.-Geographical distribution of the Hamsters; Cricetus and Cricetulus, Diploid; Mesocricetus, Tetraploid.

corded in Syria, Mesocricetus and Cricetus in Roumania, and all three have been recorded in the Caucasus. The origin of the tetraploid can have taken place in or near the Caucasus region.

Data from external animal morphology, the geological record and geographical distribution, thus support the chromosome evidence for polyploid evolution in hamsters.

\section{THE SUPPOSED ABSENCE OF POLYPLOIDS}

Polyploidy is now a recognised factor in the evolution of plants. In animals, however, the existence of polyploid evolution is still being disputed. Although it has been shown that polyploid series can be found among parthenogenetic and some hermaphrodite groups of animals, the possible existence of polyploidy is still doubted for bisexual species (White, r945, r946). Objections to the possibility of polyploidy among bisexual species has been based both on the theoretically expected sexual conditions in new polyploids, and on the absence of any definite polyploid series among related species. The theoretical objections to the establishment of polyploids (Muller, r940) have been primarily based, A, on the evidence from triploid intersexes in Drosophila, and, B, on the 
expected segregation of the sex chromosomes in tetraploids of the heterogametic sex.

A. The sex determining mechanism in Drosophila depends on the balance between the number of $\mathrm{X}$ chromosomes and the number of autosome sets (Bridges, 1939). Females are produced by an $\mathrm{X} / \mathrm{A}$ ( $\mathrm{A}=$ autosome set) of $\mathrm{r} \cdot \mathrm{O}$ and males by an $\mathrm{X} / \mathrm{A}$ ratio of 0.5 . X/A ratios above $\mathrm{I} \cdot \mathrm{O}$ produce super-females, those below 0.5 produce super-males, whereas ratios between 0.5 and $\mathrm{r} \cdot 0$ produce intersexes. Triploids with $2 \mathrm{X}+$ $3^{\mathrm{A}}$, a ratio of 0.67 , are thus intersexes. The Drosophila data, however, also shows that tetraploids with $4 \mathrm{X}+4 \mathrm{~A}$, or $2 \mathrm{X}+4 \mathrm{~A}$, or that triploids with $3 \mathrm{X}+3 \mathrm{~A}$, still possess the appropriate balance for normal sex determination. The presence of intersexes in the one class of triploids need thus not necessarily be a deterrent to the establishment of polyploids. It is further doubtful how far the Drosophila data can be generally applied to all bisexual species. Some animals may have similarities to the type of sex determination found in Melandrium. In this type, sex determination is produced by a critical balance dependant on the male determining potencies of the Y chromosome (Warmke, 1946; Westergaard, 1946). Moreover, we do not know how far the sex determining mechanism in mammals, in contrast to Drosophila, may be complicated or simplified by the action of hormones. The Drosophila data on intersexes is thus not a decisive objection to the establishment of polyploidy among all bisexual species.

B. The second theoretical objection to the establishment of polyploids (Muller, I940) is the expected segregation of the sex chromosomes in tetraploid individuals of the heterogametic sex. It is assumed that in an XXYY tetraploid, segregation of the $\mathrm{X}$ and $\mathrm{Y}$ chromosomes at meiosis would produce almost only $\mathrm{XY}$ gametes. Any possible mating between an XXXX tetraploid and an XXYY tetraploid would thus tend to produce mainly XXXY individuals. According to the Drosophila scheme of sex determination these XXXY individuals would have an abnormal X/A ratio so that they would be unable to reproduce. The XXXX tetraploids would thus be the only properly reproducing animals and the polyploid is then assumed to become effectively homogametic. There is, however, no experimental evidence in animals which has shown this supposed segregation of the sex chromosomes in the tetraploid. The experimental data does show that the establishment of tetraploidy is possible with the Melandrium type of sex determination (Warmke and Blakeslee, r940).

The original production of multivalents by the sex chromosomes is not necessarily a barrier to the establishment of polyploidy. Darlington (1939) has shown how an autosome pair of chromosomes may, in the course of evolution, behave as a sex pair. The opposite process may also take place. A multivalent association of sex chromosomes may thus be changed, during evolution, into one pair of sex chromosomes and one pair of chromosomes which behave like the autosomes. But even if the multivalent sex chromosomes persist, they need not necessarily be 
deleterious to survival. Multiple sex chromosomes can still be found in a number of animals (White, 1945). In mammals an $X_{1} Y_{2}$ sex mechanism has been reported in Potorous tridactylus, a rat kangaroo, (Sharman et al., 1950) and Sorex araneus, the common shrew, (Bovey, r949). In both cases, the segregation of the sex trivalents produces a regular distribution of the $\mathrm{X}$ and $\mathrm{Y}$ chromosomes. There are thus no general theoretical objections to the possible establishment of polyploids.

The actual absence of any definite polyploid series among related species has also been used as evidence against the existence of polyploidy in bisexual species (White, 1946). This objection is no longer valid in view of the present data on the correct chromosome numbers of the hamsters.

The scarcity of reliable data on the chromosomes of other groups, makes it difficult to estimate how far polyploid evolution has taken place in other mammals. In an effort to compare the number of chromosome arms rather than the number of chromosomes, Matthey (1949, 195 1 a) has attempted to reduce all mammalian chromosomes to what he calls " nombre fondamental" (N.F.) or "fundamental number" (F.N.). A metacentric chromosome, with two distinct arms, is counted as an F.N. of 2, and an acrocentric chromosome, with an almost terminal centromere, as an F.N. of $\mathbf{I}$. There is, however, often no clearcut difference between some metacentric chromosomes which are given as F.N. of 2, and some acrocentric chromosomes which are given as F.N. of I. In addition, small metacentric chromosomes are given as F.N. of 2 whereas large acrocentric chromosomes are only given as F.N. of $\mathrm{I}$. It has often been pointed out that it is not easy to establish the exact position of the centromere in mammalian chromosomes. Indeed, many published drawings of what are called the idiograms of mammalian chromosomes, do not include the location of the centromere. Even with good techniques the exact location of the centromere is sometimes open to doubt. These attempted calculations of "fundamental numbers " in mammals are thus of a doubtful value for estimating the magnitude of different chromosome changes.

Vertebrate and even mammalian evolution is reckoned in millions of years. There have thus been enormous possibilities for structural chromosome changes. Some animal groups may also now possess more than one basic chromosome number, a condition which is known to occur in plants (Darlington and Janaki Ammal, 1945). Changes such as the possible extinction of ancestral form, variations in basic number, and structural chromosome alterations, may now mask the existence of what had originally been produced by polyploidy. That polyploidy definitely does exist can be seen from the data on hamsters. But an evaluation of the general role of polyploidy, and of other possible changes in mammals, is at present mainly prevented by the scarcity of reliable data. 


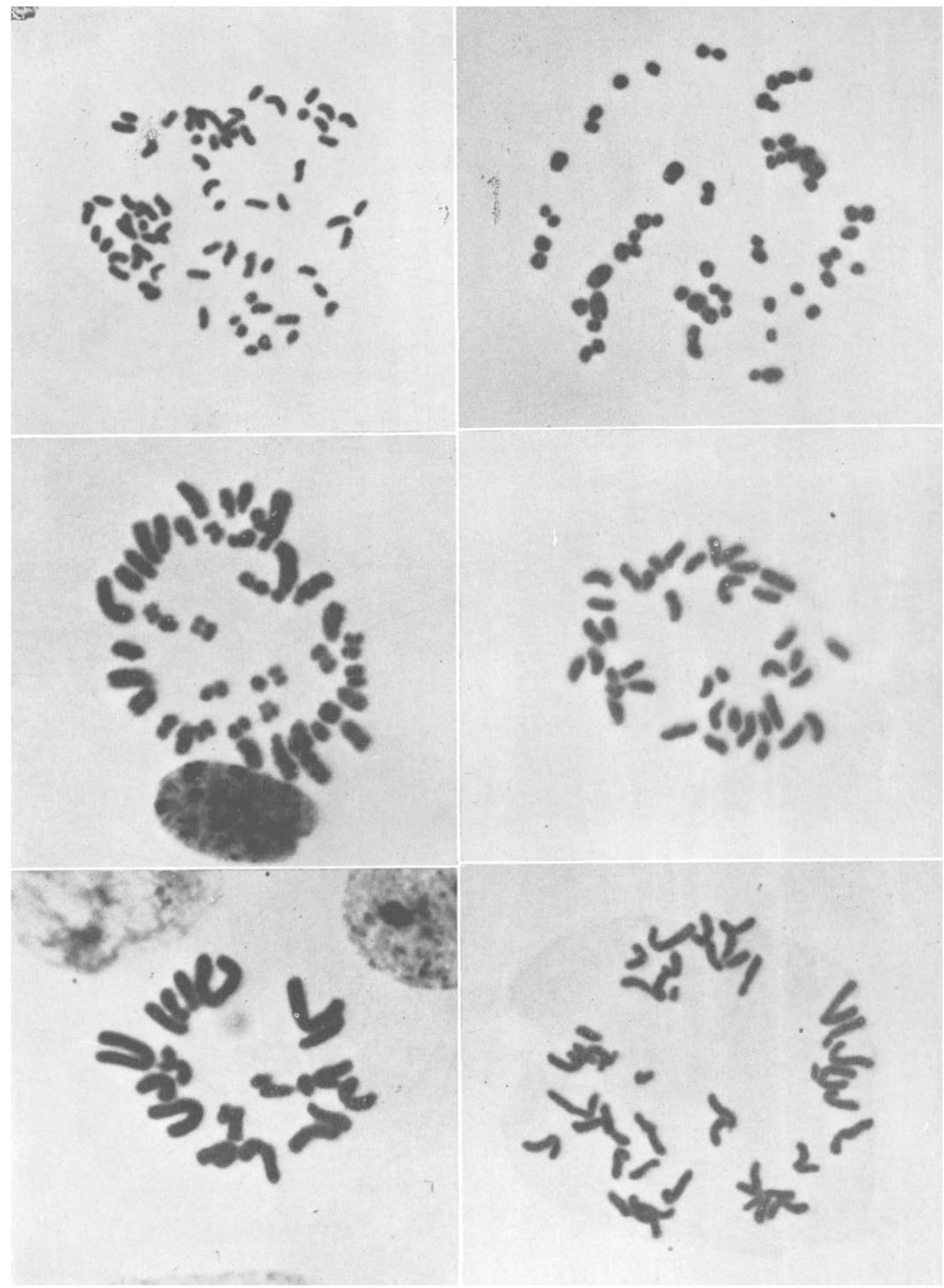

Plate I.-Microphotographs of spermatogonial cells in mammalian testes.

Feulgen squash $\times 2,000$

Fig. 1.- Tatera indica ceylonica (Ceylon gerbil) $2 n=72$.

FIG. 2.-Cavia cobaya (Guninca pig) $2 n=64$.

Fig. 3.-Rattus norvegicus (Albino rat) $2 n=42$.

Fig. 4.-Mus musculus (House mouse) $2 n=40$.

Fig. 5.-Cricetulus griseus (Striped hamster) $2 n=22$.

FiG. 6.-Mesocricetus auratus (Golden hamster) $2 n=44$. 


\section{SUMMARY}

I. A simple squash technique has given uniformly good results for mammalian chromosomes.

2. The correct chromosome numbers in the hamsters are $2 n=44$ for Mesocricetus auratus (the golden hamster), and $2 n=22$ for Cricetulus griseus (the striped hamster) and Cricetus cricetus (the common hamster).

3. The tetraploid Mesocricetus has a more limited geographical distribution than the diploids Cricetulus and Cricetus.

4. The hamsters represent a clear example of polyploid evolution among related species of mammals.

5. Polyploidy is shown to be a definite possibility in the evolution of bisexual species of animals. criticism.

Acknowledgment.-- I am indebted to Dr C. D. Darlington for suggestions and

Note added in proof. Since the above was written, Tobias (S. Afr. Four. Sci., $4^{8}$, $366-373,1952$ ) has reported $2 n=34$ in a South African gerbil Tatera brantsii draco. This number is almost half the $2 n=72$ which I have found in the Ceylon gerbil Tatera indica ceylonica. Polyploid evolution may thus also be found in the mammalian genus Tatera.

\section{REFERENCES}

Bovey, R. 1949. Les chromosomes des Chiroptéres et des Insectivores. Rev. Suisse Zool., 56, 371-46o.

BRIDGES, C. B. 1939. Cytological and genetical basis of sex in Sex and Internal Secretion and Ed. Williams \& Wilkins, pp. 15-63.

Darlington, c. D. 1939. The Evolution of Genetic Systems. Cambridge : Univ. Press. Darlington, C. D. AND Janaki AmmaI, E. Y. 1945. Chromosome Atlas of Cultivated Plants. London : Allen \& Unwin.

DARLINGton, G. D. AND LA COUR, L. F. 1947. The Handling of Chromosomes 2nd Ed. London : Allen \& Unwin.

ellerman, J. R. 1941. The Families and Genera of Living Rodents, II. London : British Museum (Natural History).

hUSTr.D, L. et al. 1945. The X-bivalent of the golden hamster. F. Hered., 36, 93-96. KOLLER, P. C. $193^{8}$. The genetical and mechanical properties of the sex chromosomes.

IV. The golden hamster. F. Genet., 36, 177-185.

KolLER, P. C. 1946. Control of nucleic acid charge in the X-chromosome of the hamster. P.R.S., B, 133, 31 3-326.

LA COUR, L. F. 1944. Mitosis and cell differentiation in the blood. P.R.S. Edin., B, $62,73-85$.

MATTHEY, R. 1949. Les Chromosomes des Vertébrés. Lausanne : Rouge.

Matthey, R. I95 I $a$. The chromosomes of the vertebrates. Adv. Genet., 4, I59-180.

matthey, R. 195I $b$. Chromosomes de Muridae. Experientia, 7, 340.

MULDAL, s. 1947. 38th J.I.H.I. Ann. Rept.

muldal, s. 1950. (Rev.) Les Chromosomes des Vertébrés. R. Matthey. Heredity, 4, 264-266. MULLER, H. J. 1940. Bearings of the "Drosophila" work on systematics in The New Systematics. Oxford : Clarendon Press, pp. 185-268.

PONTECORVO, G. I943. Meiosis in the striped hamster, etc. P.R.S. Edin., B, 62, 32-42. Sharman, G. D. et al. 1950. Multiple sex chromosomes in the marsupials. Nature, 166 , 996. 
SIMPSON, G. L. 1945. The principles of classification and a classification of mammals. Bull. Amer. Mus. Nat. History, 85, 1-350.

warmke, н. E. 1946. Sex determination and sex balance in Melandrium. Amer. 7 . Bot., 33, 648-66o.

WARMKe, H. E. AND Blakeslee, A. F. 1940. The establishment of a $4 \mathrm{~N}$ dioecious race in Melandrium. Amer. 7. Bot., 27, $75^{1-762 .}$

WESTERGAARD, M. 1946. Aberrant $Y$ chromosomes and sex expression in Melandrium album. Hereditas, 32, 419-443.

white, M. J. D. 1945. Animal Cytologv and Evolution. Cambridge : University Press.

wHite, м. J. D. 1946. The evidence against polyploidy in sexually-reproducing animals. Amer. Nat., 8o, 61 о-618. 